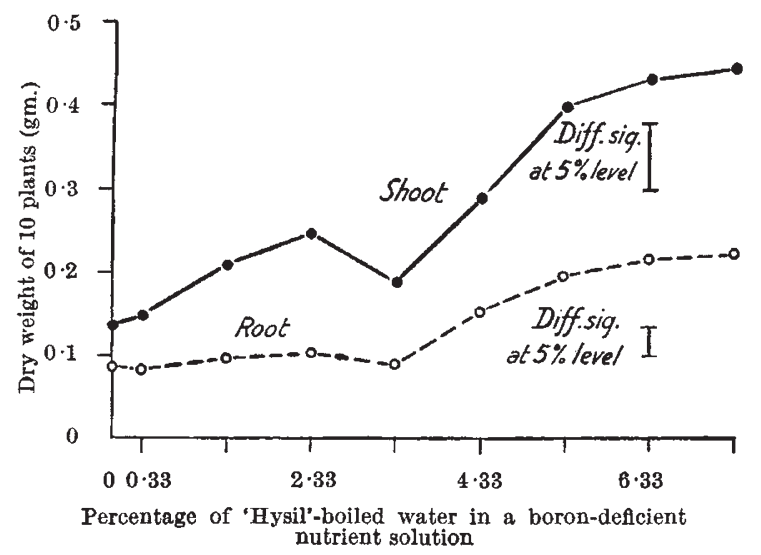

Fig. 1

The results are summarized in Fig. 1. It will be noted that where the proportion of 'Hysil'-boiled water exceeded $4 \cdot 33$ per cent of the total volume of nutrient solution, significant increases in the dry weights of both shoot and root resulted. The concentration of boron at this dilution of the 'Hysil'-boiled water was only 0.0030 p.p.m.

These findings arose from attempts made in this department to verify the claim of Eaton ${ }^{3}$ that $\beta$-indolyl acetic acid may, to some extent, replace boron as an essential element in plant growth. When aqueous solutions of this acid prepared in 'Hysil' vessels were added to boron-deficient nutrient solutions significant increases in the growth of flax were frequently obtained. This result can now be attributed, at least in part, to the boron liberated from the glassware.

In recent years much attention has been centred on the testing of a wide range of organic compounds for biological activity. It is now evident that where the level of boron is sub-optimal for the growth of the plant or plant organ, or is quite unknown, precautions should be observed to ensure that, in the preparations of solutions for test, no contamination with borosilicate glassware has occurred.

We are indebted to Dr. T. H. Rose and Mr. T. Williams, of the National Agricultural Advisory Service, Wye, for the boron estimations.

$$
\begin{aligned}
& \text { I. W. SELmaN } \\
& \text { J. R. REES } \\
& \text { J. Dilnot }
\end{aligned}
$$

Department of Biological Sciences, Wye College, University of London.

$$
\text { Feb. } 6 .
$$

${ }^{1}$ Hewitt, E. J., Tech. Comm. 22, Commonw. Bur. Hort. Crops (1952). 'Hatcher, J. T., and Wilcox, L. V., Anal. Chem., 22, 567 (1950).

- Eaton, F. M., Bot. Gaz., 101, 700 (1940).

\section{Sharpening the Microtome Knife}

SEVERAL articles have been written on the most suitable method of sharpening the knife of a microtome. The usual manner of sharpening is grinding, honing, polishing and stropping, and there are several different methods for each of those operations. There is obviously a lack of a quantitative measuring method by means of which the result of different sharpening methods can be tested. The only fairly reliable method still used is the one indicated by von Mohl'.
The edge of the microtome knife is formed by the line of intersection of the facet surfaces. Decisive for the quality of the knife are evenness and surface finish. Therefore, a good sharpening method must result in both these qualities for the facet surfaces. Just as important is a measuring method which gives an absolute measurement of the sharpening result.

A machining method which satisfies the highest demands of evenness and surface finish of steel is lapping against cast-iron. This method is, as a rule, used by the measurement workshops in factories where precision goods are manufactured. It has proved extremely advantageous for the purpose of sharpening microtome knives. Owing to its speed with regard to removing the material and its performance with regard to the evenness and surface finish, it alone can replace grinding, honing, polishing and stropping.

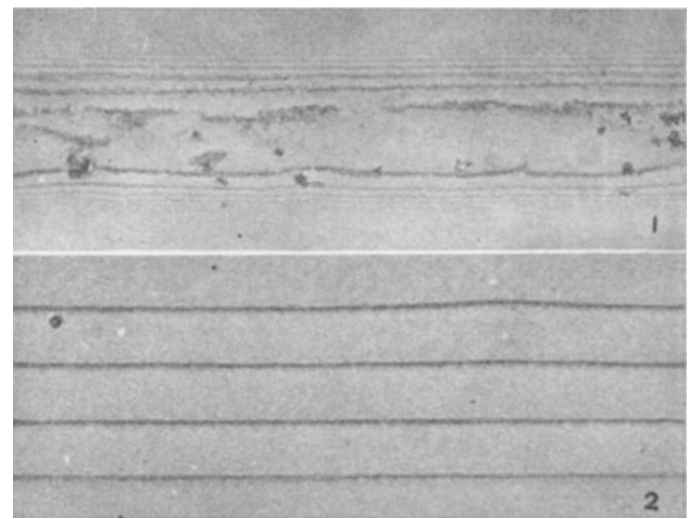

By means of multiple interference microscopy, according to Ingelstam ${ }^{2}$, it is possible to check the machined facet surfaces quantitatively. By using this method, deficiencies in evenness and surface finish can be measured to an accuracy of about $50 \mathrm{~A}$. The result of different sharpening procedures can thus be given in absolute measurement. The facet surface of a microtome knife direct from the factory (Fig. 1), and a lapped knife (Fig. 2), are shown on the accompanying interferograms $(\times 600)$. The interference fringes give a direct profile curve of the facet surface. The new knife shows signs of machining at a depth of $2000 \mathrm{~A}$., that is, rather a good surface finish but, on the other hand, variations in evenness of about $3000 \mathrm{~A}$. longitudinally and finally a considerable curving of the facet surface, which means that the clearance angle of the knife can never be adjusted against the block of tissue. The figures corresponding to the lapped surface are 50-200 and 500 A. respectively.

A more detailed report of this method will bo published later.

I am indebted to Mr. Erik Gisslén, chief engineer, and the SKF Factory, Göteborg, for their kind assistance and for the facilities placed at my disposal which made it possible to carry out this investigation. The cost of the investigation was defrayed by grant from the Swedish Medical Science Research Council.

\section{O. Hallén}

Department of Histology,

Faculty of Medicine,

Göteborg C. Jan. 30 .

${ }^{3}$ Mohl, H. v., Bot. Z., 15, 249 (1857).

- Ingelstam, E., Reports from the Laboratory of Optics, Royal Inst. of Technology, Stockholm, Sweden, No. 14i(1951). 